
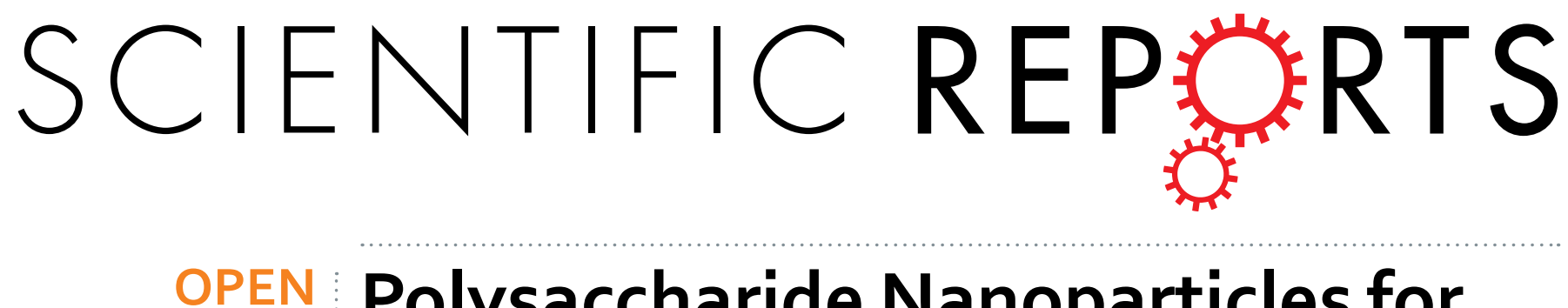

\title{
Polysaccharide Nanoparticles for Efficient siRNA Targeting in Cancer Cells by Supramolecular $\mathrm{p} K_{\mathrm{a}}$ Shift
}

Received: 09 May 2016

Accepted: 09 June 2016

Published: 01 July 2016
Ying-Ming Zhang ${ }^{1}$, Yang Yang ${ }^{1,+},{ }^{+}$Yu-Hui Zhang ${ }^{1} \&$ Yu Liu $^{1,2}$

Biomacromolecular $\mathrm{p} K_{\mathrm{a}}$ shifting is considered as one of the most ubiquitous processes in biochemical events, e.g., the enzyme-catalyzed reaction and protein conformational stabilization. In this paper, we report on the construction of biocompatible polysaccharide nanoparticle with targeting ability and lower toxicity by supramolecular $\mathrm{p} K_{\mathrm{a}}$ shift strategy. This was realized through a ternary assembly constructed by the dual host-guest interactions of an adamantane-bis(diamine) conjugate (ADA) with cucurbit[6]uril (CB[6]) and a polysaccharide. The potential application of such biocompatible nanostructure was further implemented by the selective transportation of small interfering RNA (siRNA) in a controlled manner. It is demonstrated that the strong encapsulation of the ADA's diammonium tail by $\mathrm{CB}[6]$ not only reduced the cytotoxicity of the nano-scaled vehicle but also dramatically enhanced cation density through an obvious positive macrocycle-induced $\mathrm{p} K_{\mathrm{a}}$ shift, which eventually facilitated the subsequent siRNA binding. With a targeted polysaccharide shell containing a cyclodextrin-hyaluronic acid conjugate, macrocycle-incorporated siRNA polyplexes were specifically delivered into malignant human prostate PC-3 cells. The supramolecular polysaccharide nanoparticles, the formation of which was enabled and promoted by the complexation-assisted $\mathrm{p} K_{\mathrm{a}}$ shift, may be used as a versatile tool for controlled capture and release of biofunctional substrates.

The states of protonation in solution, which can be quantitatively measured by the acidity constant of $\mathrm{p} K_{\mathrm{a}}$, have critical relevance to our biomedical and physiological events ${ }^{1-4}$. The specific function of a given chemical group as a nucleophiles, electrophiles, or general acid-base catalysts in myriad of biological reactions can largely lies in its state of protonation. Significantly, the precise control of prototropic equilibrium can also profoundly affect the electrostatic stabilization of native biomacromolecules by facilitating the favorable opposite-charge attraction and avoiding the unfavorable Coulombic repulsion. The primary electrostatic attraction originating from $\mathrm{p} K_{\mathrm{a}}$ shifting is vital to many biological processes, by which some secondary interactions, such as hydrophobic and hydrogen bonding interactions, can be further stimulated to propagate the formation of well-organized superstructures and to eventually achieve diverse biological function $s^{5-8}$. Thus, the elaborate optimization and implementation of electrostatic force through $\mathrm{p} K_{\mathrm{a}}$ regulation is useful in molecular-level understanding of the multiple noncovalent contributions in biology-related systems.

Recent studies of supramolecular chemistry have significantly improved our understanding of noncovalent interactions, which is a prerequisite for mimicking various biological processes ${ }^{9-12}$. In this regard, the use of synthetic macrocycles has greatly expanded the roles of chemical synthesis and the range of methodologies employed in modern nanomedicine ${ }^{13-17}$. In particular, macrocycle-based supramolecular approach may provide a convenient and powerful tool for the improvement of biocompatiblility and reducing side effects, mainly due to its immense advantages to regulate the physicochemical properties of individual subunits or components by integrating the multiple noncovalent interactions ${ }^{18-22}$. It is also noteworthy that macrocyclic encapsulation has been proven to alter chemical reactivity and modify the protonation-deprotonation equilibria of included small molecules through a complexation-induced $\mathrm{p} K_{\mathrm{a}}$ shift $\operatorname{method}^{23,24}$. Therefore, one can believe that the rational combination of macrocyclic receptors with efficient $\mathrm{p} K_{\mathrm{a}}$ regulation will be developed into a promising approach to bind ionized bioactive substrates in a controlled manner.

${ }^{1}$ Department of Chemistry, State Key Laboratory of Elemento-Organic Chemistry, Nankai University, Tianjin 300071, P. R. China. ${ }^{2}$ Collaborative Innovation Center of Chemical Science and Engineering (Tianjin), Tianjin 300071, P. R. China. ${ }^{\dagger}$ Present address: School of Chemical Engineering and Technology, Hebei University of Technology, Tianjin 300130, P. R. China. Correspondence and requests for materials should be addressed to Y.L. (email: yuliu@nankai. edu.cn) 

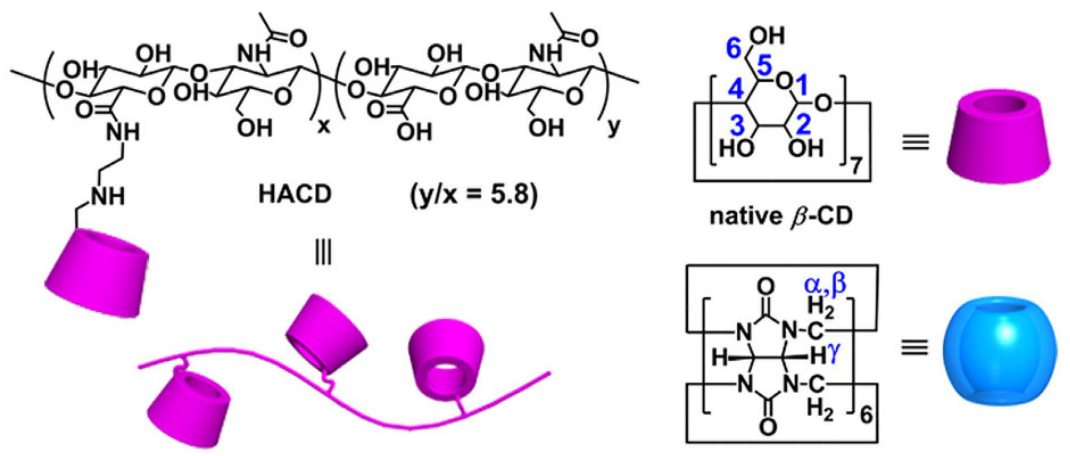

native $\beta$-CD
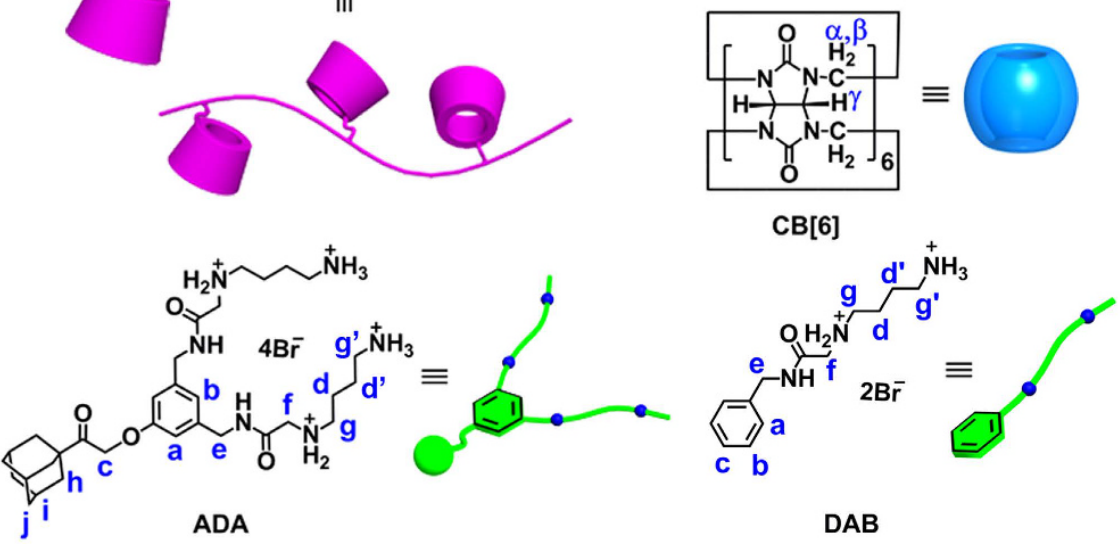

Figure 1. Molecular structures and proton designations of ADA, DAB, HACD and CB[6]. HACD carries $\beta$-CD at every 6.8 repeating units. ADA carries one adamantyl head and two polyammonium tails and is simultaneously bound to $\beta-\mathrm{CD}$ and $\mathrm{CB}[6]$.

Moreover, there is a general consensus that the binding process with nucleic acids always occurs via electrostatic interaction, which is ubiquitously practiced as the reliable noncovalent driving force owing to the inherently anionic property of naked nucleic acids ${ }^{25,26}$. This principle inspired us to hypothesize that a controlled nucleic acid binding may be realized by implementing the complexation-induced $\mathrm{p} K_{\mathrm{a}}$ shift strategy to adjust the acid-base equilibria in appropriate guests. In this work, the application of supramolecular $\mathrm{p} K_{\mathrm{a}}$ shift was implemented by the controlled binding of nucleic acids. Through a large and positive cucurbituril-induced supramolecular $\mathrm{p} K_{\mathrm{a}}$ shift, we found that small interfering RNA (siRNA) can be readily assembled into a macrocycle-based nanosystem for targeted delivery into cancer cells. The association of cucurbituril could greatly facilitate the electrostatic attraction and the protonation of polyamine groups in a triad guest at a neutral $\mathrm{pH}$ and significantly increases the cationic density for efficient siRNA packaging. Meanwhile, the biodegradable cyclodextrin-tethered hyaluronic acid shell, which is specifically recognized by hyaluronic acid receptors that are overexpressed on the surface of cancer cells, enhances the biocompatibility of the overall delivery system while ensuring targeting capability ${ }^{27,28}$. Besides the desirable targeting capability, the siRNA-bound polyplexes, which are derived from the selective bimodal molecular recognition of the adamantane-bis(diamine) conjugate (ADA) with $\beta$-cyclodextrin $(\beta$-CD) and cucurbit[6] uril (CB[6]), exhibit higher transfection efficiency than that observed for the individual ammonium guest and conventional transfection reagents. It can be anticipated that the effective regulation of the $\mathrm{p} K_{\mathrm{a}}$ value of the amino group in ADA by host-guest complexation and the selective delivery of nucleic acids in target cells may enable practical applications of macrocycle-based non-viral vectors in gene therapy. Although some relevant studies on protonation-directed gene silence and hyaluronic acid-based delivery systems have been separately reported ${ }^{29-31}$, we herein report a quite simple and practical method to precisely adjust the cation density of polysaccharide nanoparticles by supramolecular $\mathrm{p} K_{\mathrm{a}}$ shift. To the best of our knowledge, this is the first example of implementing macrocycle-induced $\mathrm{p} K_{\mathrm{a}}$ shift concept in the selective transportation of nucleic acids.

\section{Results and Discussion}

Synthesis of CB[6]-ADA-HACD assembly. $\quad \beta$-CD-modified hyaluronic acid (HACD) carries $17 \beta$-CD units on average in a HA chain and functions as the polysaccharide shell. HACD was prepared by the amidation of hyaluronic acid with mono-6-deoxy-6-(2-aminoethylamino)- $\beta$ - $\mathrm{CD}$, according to procedures reported previously ${ }^{32}$. The degree of substitution employed was suitable for balancing the specific recognition by HA receptor-overexpressing cancer cells and the multivalent binding of hydrophobic substrates. The triad guest molecule (ADA, 1) carries one adamantyl moiety and two protonated 1,4-diamine chains. ADA was prepared in 4 steps from adamantyl bromomethyl ketone (2) and the pentafluorophenyl ester of Cbz-protected 4-aminobutylaminoacetic acid (6) (see Supplementary Figs S1-S18). As illustrated in Fig. 1, ADA carries two types of independent guest moieties. One is the bulky adamantyl group to be included in the $\beta$-CD cavity; the other is the 1,4-diammonio moieties that are to be bound to $\mathrm{CB}[6]$. The pendant polycationic sidechains of ADA are also expected to electrostatically interact with the anionic phosphate backbones of siRNA ${ }^{33-35}$. A ternary $\mathrm{CB}[6]-\mathrm{ADA}-\mathrm{HACD}$ complex that benefited from the bimodal binding of ADA with two different types of macrocycles and was able to target cancer cells was readily and selectively obtained.

Molecular Binding Behaviors of ADA with $\beta-C D$ and $C B[6]$. Before examining complexation with nucleic acid, the affinities between ADA and HACD and $\mathrm{CB}[6]$ were evaluated by NMR spectroscopy. Native 


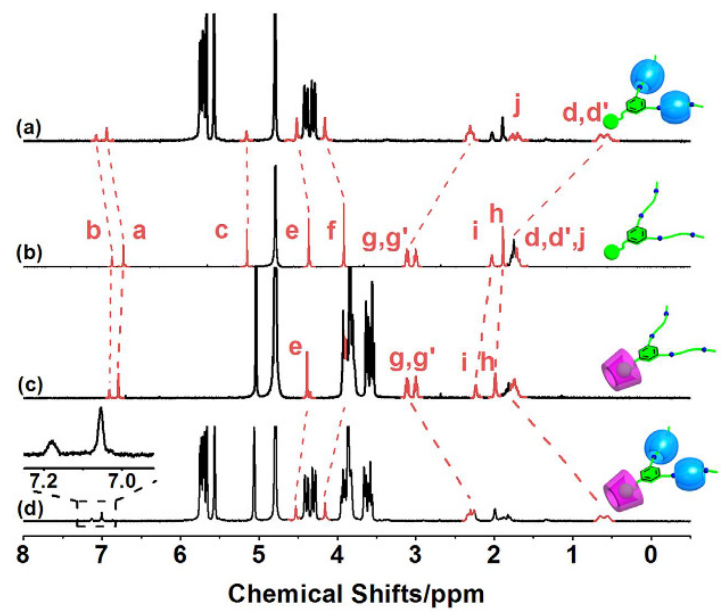

Figure 2. ${ }^{1} \mathrm{H}$ NMR titration of $\mathrm{DAB}$ with $\beta-\mathrm{CD}$ and $\mathrm{CB}[6]$ in the molecular self-assembling process. ${ }^{1} \mathrm{H}$ NMR spectra at $400 \mathrm{MHz}$ of (a) ADA-CB[6] complex, (b) ADA, (c) ADA- $\beta$-CD complex, and (d) $\beta$-CDADA-CB[6] complex in $\mathrm{D}_{2} \mathrm{O}$ at $25^{\circ} \mathrm{C}$. Inset in (d): Magnified area of phenyl protons ([ADA] $=1.0 \mathrm{mM},[\mathrm{CB}[6]]$ $=2.0 \mathrm{mM}$, and $[\beta-\mathrm{CD}]=3.0 \mathrm{mM})$.

$\beta$-CD was used as a reference for HACD. The binding stoichiometry was determined as 1:1 for $\beta$-CD-ADA complexation via a Job analysis of the peak shifts of the adamantyl $\mathrm{H}_{\mathrm{h}}$ proton originally located at $\delta 1.95 \mathrm{ppm}$ (see Supplementary Fig. S19). Using 1:1 stoichiometry, the association constant $\left(K_{\mathrm{a}}\right)$ was determined to be $6.09 \times 10^{4} \mathrm{M}^{-1}$; the chemical shift changes of the adamantane proton of ADA were analyzed upon titration with native $\beta$-CD (see Supplementary Fig. S20). As this $K_{\mathrm{a}}$ value obtained is comparable to or even larger than those reported for adamantanols and adamantanecarboxylates, which typically range from $10^{3}$ to $10^{5} \mathrm{M}^{-1}$, the polyammonium sidechains in ADA do not appear to significantly affect the intermolecular complexation of ADA by $\beta$-CD ${ }^{36,37}$. Meanwhile, the butane-1,4-diamine derivative bearing single ammonium arm (DAB) was employed as the reference molecule to evaluate the complexation behaviors between $\mathrm{CB}[6]$ and the ammonium sidechain (see Supplementary Figs S21-S26). Isothermal titration calorimetry (ITC) measurements showed that this binding process was governed in a thermodynamically favorable way with negative enthalpy and positive entropy changes, accompanied by the high binding affinity up to $10^{6} \mathrm{M}^{-1}$ (see Supplementary Fig. S27). These molecular binding parameters reveal that the bifunctional ADA molecule could be concurrently associated with $\beta$-CD and $\mathrm{CB}[6]$ to form a stable inclusion complex in water, and more importantly, this extremely strong binding would facilitate the eventual formation of siRNA polyplexes, as described below.

Figure $2 \mathrm{a}-\mathrm{d}$ illustrate the individual and simultaneous binding behaviors of $\mathrm{ADA}$ with $\beta$ - $\mathrm{CD}$ and/or $\mathrm{CB}[6]$. The characteristic peaks of the ADA's aliphatic tails shifted to the upper field upon complexation with CB[6]; the $\mathrm{H}_{\mathrm{d}, \mathrm{d}}$, and $\mathrm{H}_{\mathrm{g}, \mathrm{g}}$, protons displayed pronounced complexation-induced upfield shifts of 1.13 and $0.78 \mathrm{ppm}$, respectively. Conversely, the adjacent $\mathrm{H}_{\mathrm{a}, \mathrm{b}, \mathrm{e}, \mathrm{f}}$ protons showed downfield shifts. The adamantyl $\mathrm{H}_{\mathrm{h}, \mathrm{i}}$ protons were nearly unaffected in the presence of $\mathrm{CB}[6]$. These contrasting NMR spectral shifts demonstrate that the pendant diammonium sidechains are tightly bound to $\mathrm{CB}[6]$ through an ion-dipole interaction; the aromatic and adamantane residues remain unaffected outside the cavity of $\mathrm{CB}[6]$ (Fig. 2a,b) ${ }^{38}$.

In the case of the $\beta$-CD-ADA complex, the $\mathrm{H}_{\mathrm{d}, \mathrm{d}}$, and $\mathrm{H}_{\mathrm{g}, \mathrm{g}}$, protons in the sidechain were completely unaffected. The aromatic $\mathrm{H}_{\mathrm{a}}$ and $\mathrm{H}_{\mathrm{b}}$ protons of ADA shifted downfield only slightly ( 0.06 and $0.04 \mathrm{ppm}$, respectively). The adamantyl $\mathrm{H}_{\mathrm{h}}$ proton was subject to a larger downfield shift of $0.11 \mathrm{ppm}$ due to the hydrophobic interactions of the adamantine moiety in the $\beta$-CD cavity (Fig. $2 \mathrm{~b}, \mathrm{c})$. When both of the macrocycles $(\beta$-CD and $\mathrm{CB}[6])$ were added to an ADA solution, the overall chemical shift changes of the ADA protons (Fig. $2 \mathrm{~d}$ ) were nearly equivalent to the sum of the shift changes caused independently by $\mathrm{CB}[6]$ (Fig. 2a) and $\beta$-CD (Fig. 2c); the observed additivity of the chemical shift changes suggests the non-interfering complexation of both macrocycles with ADA.

Nuclear Overhauser enhancement spectral (NOESY) examinations revealed NOE cross-peaks between the $\mathrm{H}_{\mathrm{h}, \mathrm{i}}$ protons of adamantane and the $\mathrm{H}_{3,5}$ protons of the CD interior (peaks A and B in Supplementary Fig. S28). Furthermore, the NOE cross-peaks between the $\mathrm{CB}[6]$ 's $\mathrm{H}_{\alpha, \gamma}$ protons and the $\beta$-CD's $\mathrm{H}_{2,3}$ protons (peaks $\mathrm{C}$ and $\mathrm{D}$ in Supplementary Fig. S28) provide strong evidence for the coexistence of two macrocycles in close proximity in the ternary complex. These ${ }^{1} \mathrm{H}$ NMR titration results unequivocally corroborate that a ternary $\beta$-CD-ADA$\mathrm{CB}[6]$ complex is exclusively formed through simultaneous specific binding of the adamantyl head of ADA by $\beta$-CD and the diammonium tails by $\mathrm{CB}[6]$.

Supramolecular $\mathrm{p} K_{\mathrm{a}}$ shift of ADA-CB[6] complex. As synthetic vectors for nucleic acid binding mediated by ammonium ions are very sensitive to the $\mathrm{pH}$ in solution, it is essential to take into account the $\mathrm{pH}$ effect. The optimal charge density (or number of charges) in electrostatically driven complexation with biomacromolecules must also be determined ${ }^{39-42}$. In our case, the $\mathrm{H}_{\mathrm{f}}$ proton in ADA and the ADA-CB[6] complex was very sensitive to the $\mathrm{pH}$ in solution; therefore, this proton was monitored during the $\mathrm{pH}$ titration experiments. As discerned from the plot of chemical shifts versus $\mathrm{pH}$, it is found that the titration curve was significantly shifted to higher $\mathrm{pH}$ region in ADA-CB[6] complex, suggesting that the degree of protonation in ADA would be greatly 

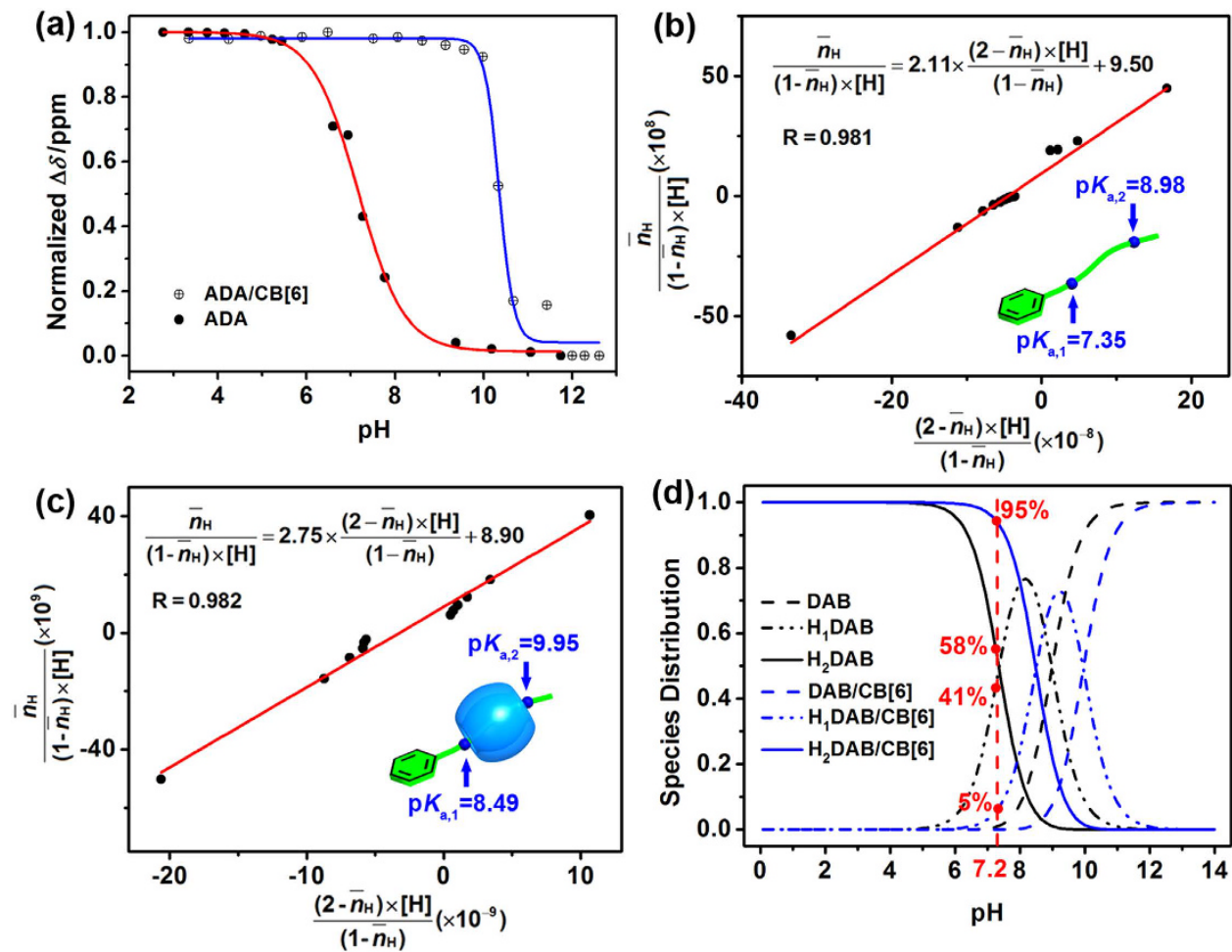

Figure 3. Supramolecular $\mathrm{p} K_{\mathrm{a}}$ shift of DAB-CB[6] complex. (a) ${ }^{1} \mathrm{H}$ NMR titration curves for free ADA and $\mathrm{ADA}-\mathrm{CB}[6]$ complex by monitoring $\mathrm{H}_{\mathrm{f}}$ proton (see Fig. 1) upon variations in $\mathrm{pH}$ in aqueous solutions at $25^{\circ} \mathrm{C}$, which revealed a different degree of protonation induced by the complexation of ADA with $\mathrm{CB}[6]$ $([\mathrm{ADA}]=0.5 \mathrm{mM}$ and $[\mathrm{CB}[6]]=1.0 \mathrm{mM})$; for the original data, see Supplementary Fig. S29; potentiometric fitting curve and $\mathrm{p} K_{\mathrm{a}}$ values calculation of $(\mathbf{b}) \mathrm{DAB}$ and $(\mathbf{c}) \mathrm{DAB}-\mathrm{CB}[6]$ system $([\mathrm{DAB}]=0.5 \mathrm{mM}$ and $[\mathrm{CB}[6]]=1.0 \mathrm{mM}) ;(\mathbf{d}) \mathrm{pH}$-dependent species distribution plot for the $\mathrm{DAB}-\mathrm{CB}[6]$ system. The distributions were obtained using the calculated $\mathrm{p} K_{\mathrm{a}, 1}$ and $\mathrm{p} K_{\mathrm{a}, 2}$ values. The $\mathrm{H}_{1} \mathrm{DAB}$ and $\mathrm{H}_{2} \mathrm{DAB}$ indicate the singly and doubly protonated species of $\mathrm{DAB}$, respectively.

changed in the presence of CB[6] (Fig. 3a and Supplementary S29). Moreover, it can be seen that the corresponding chemical shift changes of DAB took on similar characteristics in the protons of ADA upon association with $\mathrm{CB}[6]$; that is, the protons of diamine tail $\left(\mathrm{H}_{\mathrm{d}, \mathrm{d}}\right.$ and $\left.\mathrm{H}_{\mathrm{g}, \mathrm{g}}\right)$ underwent a pronounced upfield shift $(-1.08$ and $-0.69 \mathrm{ppm}$, respectively), whereas the ones of aromatic head $\left(\mathrm{H}_{\mathrm{a}-\mathrm{c}}\right)$ were almost unaffected (see Supplementary Fig. S30). These ${ }^{1} \mathrm{H}$ NMR chemical shift changes demonstrate that the ammonium sidechains in ADA and DAB could be exclusively encapsulated by $\mathrm{CB}[6]$. Therefore, $\mathrm{DAB}$ was used as the reference compound to quantitatively investigate the complexation-induced $\mathrm{p} K_{\mathrm{a}}$ changes in the potentiometric titrations (Fig. $\left.3 \mathrm{~b}, \mathrm{c}\right)$. The results clearly showed that there was an obvious $\mathrm{p} K_{\mathrm{a}}$ shift upon complexation with $\mathrm{CB}[6]\left(\Delta \mathrm{p} K_{\mathrm{a}, 1}=1.1\right.$ and $\left.\Delta \mathrm{p} K_{\mathrm{a}, 2}=1.0\right)$. As shown in Fig. 3d, the species distribution of doubly protonated DAB in the absence and presence of $\mathrm{CB}[6]$ was accordingly calculated as 58\% and 95\%, respectively, in an aqueous solution at $\mathrm{pH} 7.20$ and meanwhile, the content of singly protonated species sharply decreased from $41 \%$ to $5 \%$. These results demonstrate that the monocationic DAB could be largely converted into the dicationic one with assistance of $\mathrm{CB}[6]$, thus resulting in a high density of positive charges in neutral solution.

Furthermore, complexation-enhanced protonation was confirmed by comparing the ESI mass spectra of ADA in the presence and absence of CB[6]. ADA exhibited a doubly charged parent peak at $\mathrm{m} / z 293$ in the absence of $\mathrm{CB}[6]$; however, a quadruple-charged parent peak for the ADA-CB[6] complex was found at $m / z 645$ in the presence of $\mathrm{CB}[6]$ (see Supplementary Figs S18 and S31). These results jointly demonstrate that the diamine sidechains of ADA are fully protonated once complexed with $\mathrm{CB}[6]$, even in neutral solutions ${ }^{43}$. Crucially, this $\mathrm{CB}[6]$-induced $\mathrm{p} K_{\mathrm{a}}$ shift significantly increases the positive charge density of the resulting assembly under the physiological conditions. This finding was validated by the siRNA binding assay, as described below.

Characterization of siRNA-bound polyplexes. The enhanced cation density of ADA by the $\mathrm{CB}[6]$-induced $\mathrm{p} K_{\mathrm{a}}$ shift enabled us to prepare siRNA-bound polyplexes by simply mixing solutions of siRNA and the $\mathrm{CB}[6]-\mathrm{ADA}-\mathrm{HACD}$ complex. The morphological and structural features of the siRNA-bound polyplexes prepared in this manner were examined by atomic force microscopy (AFM) and transmission electron microscopy (TEM). The original CB[6]-ADA-HACD complex appeared as a loose nanoparticulate with a high aspect ratio. Once packed with siRNA, the polyplex become more compact in size; this is due to the neutralization of charges between polyanionic siRNA and the polycationic ternary complex (see Supplementary Figs S32 and S33). As exemplified in Fig. $4 \mathrm{a}$,b, the average height of the polyplex measured by AFM was $25 \pm 5 \mathrm{~nm}$. The siRNA aggregates formed upon complexation with the $\mathrm{CB}[6]-\mathrm{ADA}-\mathrm{HACD}$ complex were considered to be this size. TEM 


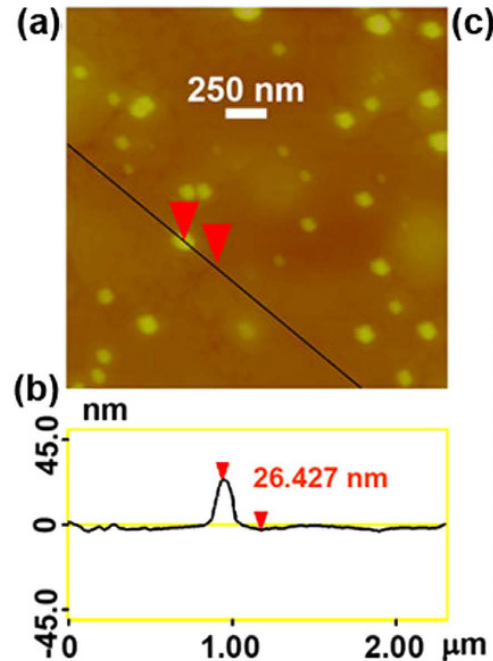

(e)

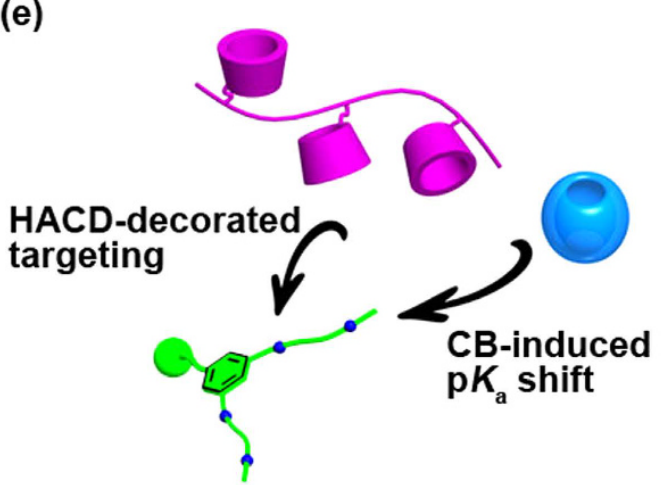

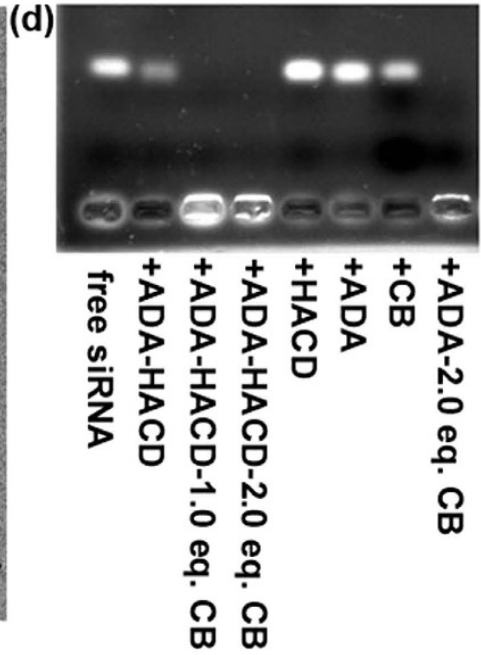

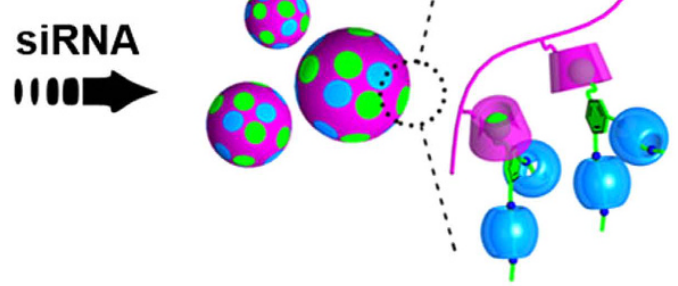

Supramolecular siRNA polyplexes

Figure 4. Morphological characterization and electrophoretic mobility of ternary assembly mixed with siRNA. (a) AFM image, (b) height profile, (c) TEM image of siRNA condensed by CB[6]-ADA-HACD triads (Inset: magnification); (d) agarose gel electrophoresis assay of $\mathrm{ADA}, \mathrm{CB}[6]$, and their complexes with negative control siRNA; the ADA: $\mathrm{CB}$ [6] ratio in (d) was fixed at 1:2; and (e) schematic illustrations of the assembling process of siRNA with $\mathrm{CB}[6]-\mathrm{ADA}-\mathrm{HACD}$ triads.

images revealed a number of solid nanoparticles with an average diameter of $39 \pm 4 \mathrm{~nm}$. These findings were in agreement with the average height measured by AFM (Fig. 4c). The spherical morphology and the nanoparticle size observed confirm that the $\mathrm{CB}[6]-\mathrm{ADA}-\mathrm{HACD}$ assembly was able to properly condense siRNA. Such condensation facilitates HA receptor-mediated internalization in cancer cells.

Subsequently, siRNA binding behavior was examined by analyzing electrophoretic mobility at different $\mathrm{N} / \mathrm{P}$ ratios (i.e., the charge ratio of cationic ammonium in ADA to anionic phosphate in siRNA). As shown in Supplementary Fig. S34a, siRNA was completely condensed by the ADA-CB[6] complex at N/P $\geq 20$. Hence, the $\mathrm{N} / \mathrm{P}$ ratio was fixed at 20 in the following cellular experiments. Additional control experiments were performed to further elucidate the roles of $\mathrm{CB}[6]$ in the siRNA binding process. Among the supramolecular hosts and complexes examined, $\mathrm{ADA}$ or $\mathrm{CB}[6]$ alone did not cause any appreciable condensation (see Supplementary Fig. S34b,c). These findings provided convincing evidence for CB-promoted siRNA condensation and were consistent with the sufficient protonation of ADA after binding with $\mathrm{CB}[6]$ under neutral conditions. Interestingly, the condensation effect of the ADA-CB[6] complex does not appear to be seriously affected by HACD (see lanes $2-5$ in Fig. 4d). This is likely due to the steric hindrance of $\mathrm{CB}[6]$ encapsulation at the diammonium sites, which keeps the carboxylate anions of HACD away from the positively charged diammonium sidechains of ADA. In contrast, no free siRNA was observed when mixed with ADA and a sufficient amount of $\mathrm{CB}[6]$. This result confirms that the siRNA-condensing capability of ADA is significantly improved in the presence of $\mathrm{CB}[6]$.

Cytotoxicity of the CB[6]-ADA-HACD complex. It is known that high-density of positive charges in transfection reagents used for DNA and RNA delivery can seriously damage cytomembranes and organelles and may lead to serious cytotoxicity toward target cells ${ }^{44-50}$. First, MTT assay was carried out to evaluate the cytotoxicities of the $\mathrm{CB}[6]-\mathrm{ADA}-\mathrm{HACD}$ assembly and Lipofectamine 2000. It was found that the ternary assembly exhibited very high cell viability $(>85 \%)$ in PC-3 cells at concentrations up to $340 \mu \mathrm{M}$. In comparison, Lipofectamine 2000 showed significant cytotoxicity (cell viability $<50 \%$ ) under the same experimental conditions (see Supplementary Fig. S35). These data demonstrate that the obtained ternary assembly has a much lower cytotoxicity compared with the conventional transfection reagent Lipofectamine 2000. 
(a)

PC-3 cell lines $24 \mathrm{~h}$
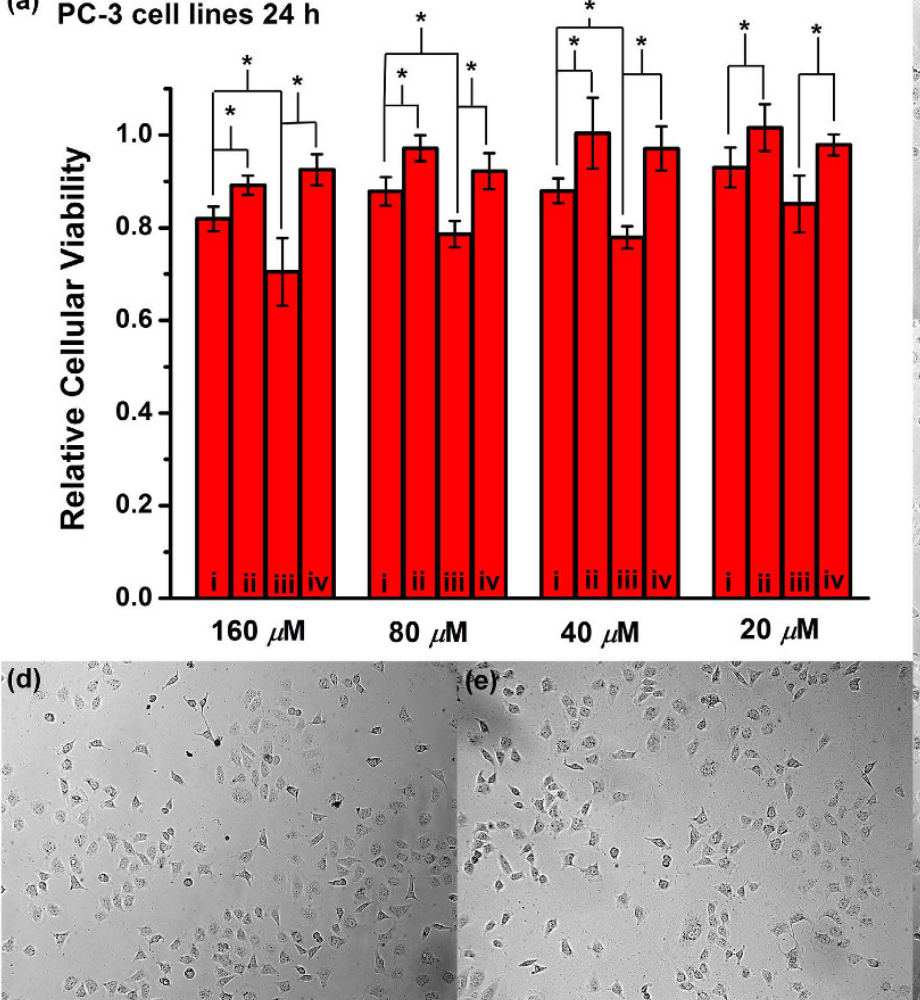

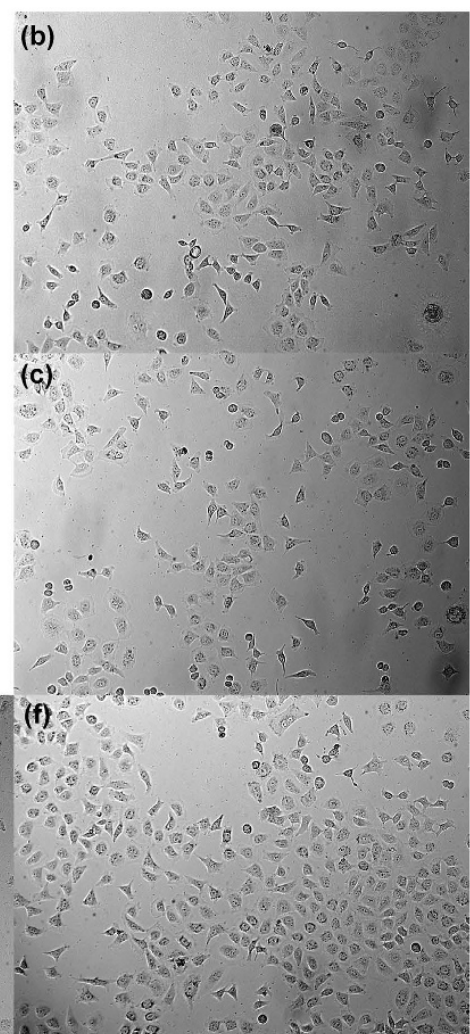

Figure 5. Cytotoxicity experiments of PC-3 cells after $24 \mathbf{h}$. (a) Relative cellular viabilities of PC-3 cells upon the addition of (i) ADA, (ii) ADA + $\mathrm{CB}$ [6], (iii) ADA + HACD, and (iv) $\mathrm{CB}[6]+\mathrm{ADA}+\mathrm{HACD}$ at 20-160 $\mu \mathrm{M}$ after $24 \mathrm{~h}$. Statistically significant differences are indicated with asterisks $(p<0.05)$. Photographs of PC-3 cells: (b) blank control and upon the addition of (c) ADA, (d) ADA + CB[6], (e) ADA + HACD, and (f) CB[6] $+\mathrm{ADA}+\mathrm{HACD}$.

Next, we performed a series of preliminary cytotoxicity experiments to evaluate the safety of the CB[6]-ADAHACD supramolecular complex in PC-3 human prostatic cancer cells prior to the assessment of transfection effects. As shown in Fig. 5, ADA (column i), the ADA-CB[6] complex (column ii), the ADA-HACD complex (column iii), and the CB[6]-ADA-HACD complex (column iv) at concentrations varying from 20 to $160 \mu \mathrm{M}$ were added to PC-3 cancer cells. After incubation for $24 \mathrm{~h}, \mathrm{ADA}$ exhibited considerable cytotoxicity at $160 \mu \mathrm{M}$ due to the positive charge of the diammonium sidechains; the relative cellular viability was $82 \%$. This viability increased to $93 \%$ when the ADA concentration decreased to $20 \mu \mathrm{M}$. Because of the protection effect of $\mathrm{CB}[6]$, the toxicity of $\mathrm{ADA}$ was reduced upon the addition of $\mathrm{CB}[6]$; significantly higher relative cellular viabilities of 90-100\% were achieved. Conversely, the supramolecular complex ADA-HACD showed more intense cytotoxicity than ADA; a relative cellular viability of $70 \%$ was observed at $160 \mu \mathrm{M}$. This was attributable to the HA receptor-mediated internalization of ADA-HACD into cancer cells and the increased ADA concentration at the cytomembrane and cytoplasm of PC-3 cancer cells. Intriguingly, the CB[6]-ADA-HACD complex showed almost negligible cytotoxicity in PC-3 cells; the relative cellular viabilities were 93-98\%. The morphological characteristics of PC-3 cells were also consistent with results obtained from the cytotoxicity experiments (Fig. 5b-f). In addition, although relatively higher cytotoxicity was observed for $48 \mathrm{~h}$, the protection effect of $\mathrm{CB}[6]$ and the non-toxicity of the $\mathrm{CB}[6]-\mathrm{ADA}-\mathrm{HACD}$ complex toward the target cell could be verified by the moderate viability percentages at relatively lower concentration (see Supplementary Fig. S36). These results allow us to conclude that the $\mathrm{CB}[6]-\mathrm{ADA}-\mathrm{HACD}$ complex is essentially nontoxic to target cells. Hence, the concentration of the ternary complex used for transfection experiments was fixed at $17 \mu \mathrm{M}$; no appreciable side effect was observed in target cells at this concentration.

Although the degree of protonation in ADA could dramatically increase by CB-induced $\mathrm{p} K_{\mathrm{a}}$ shift, the ADA$\mathrm{CB}[6]$ complex was less cytotoxic than ADA alone. These findings may be jointly attributed to the charge distribution and steric stabilization of the cationic diammonium sidechains in ADA by $\mathrm{CB}[6]$. That is, the complexation with $\mathrm{CB}[6]$ can greatly delocalize the intensive positive charges of ADA through the $\mathrm{N}^{+} \ldots \mathrm{O}^{\delta-}$ ion-dipole interconnection working at ammonium sites in ADA and carbonyl groups in $\mathrm{CB}$ [6], which is frequently observed in the crystalline complexes between $\mathrm{CB}$ and cationic molecules ${ }^{51}$. Moreover, $\mathrm{CB}[6]$ also acts as a sterically demanding component surrounding the positively charged centers to make the system more rigid. This structural feature could prohibit the close location between oppositely charged ionic components, which may allow the dissociation of siRNA at the delivery site. In comparison, the isolated positive charges without the protection of $\mathrm{CB}[6]$ in $\mathrm{ADA}$ led to the relatively high cytotoxicity. 

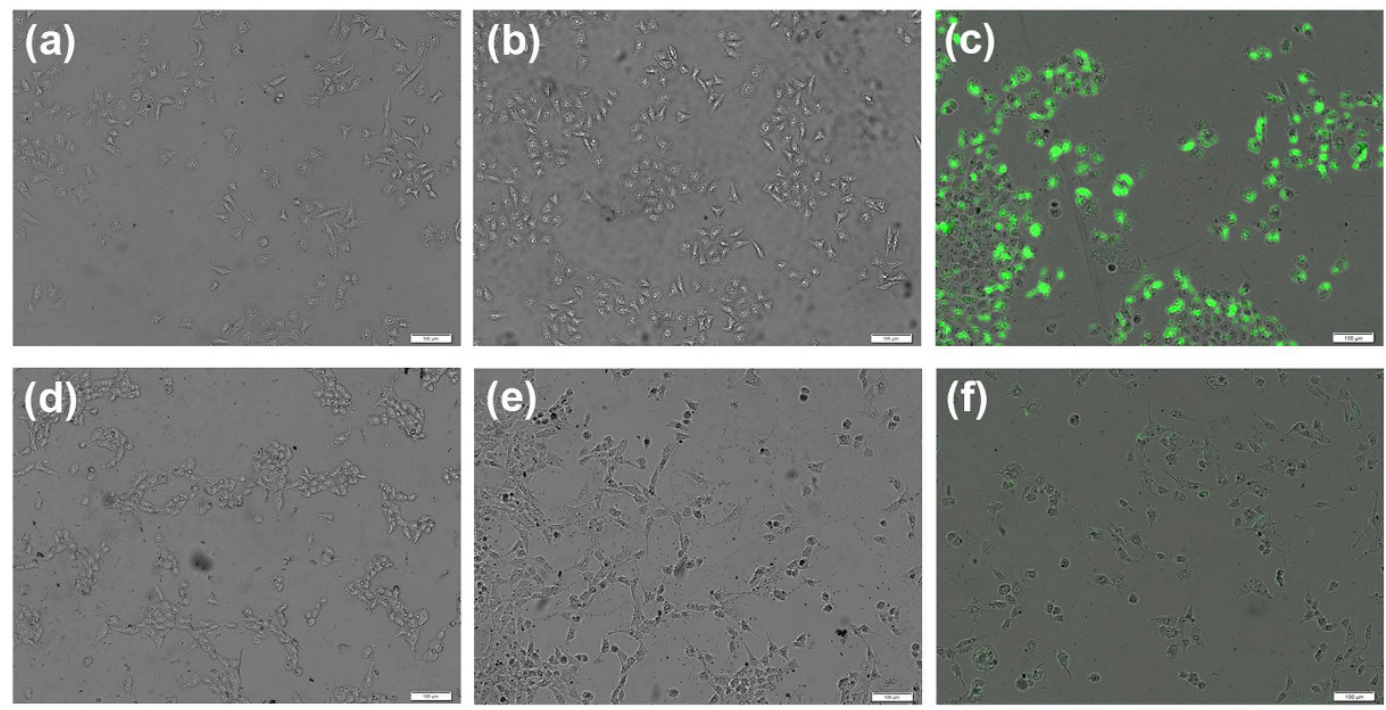

Figure 6. Selective uptake of FAM-siRNA by the supramolecular complexes and assembly. Fluorescence microscopic images of $(\mathbf{a}-\mathbf{c})$ PC-3 and (d-f) NIH3T3 cells incubated with FAM-siRNA containing (a,d) medium, (b,e) the ADA-HACD complex, and $(\mathbf{c}, \mathbf{f})$ the CB[6]-ADA-HACD assembly for $5 \mathrm{~h}$.

To further validate the enhancement of the siRNA binding process by supramolecular $\mathrm{p} K_{\mathrm{a}}$ shift, the uptake of the complex into target cancer cells was studied by confocal fluorescence microscopy using 6-carboxy-fluorescein phosphoramidate (FAM)-labeled siRNA. As shown in Fig. 6a,d, no fluorescence was detected in normal fibroblast NIH3T3 cells or in human prostate PC-3 cancer cells. This finding indicated that free FAM-siRNA cannot enter into cells without the assistance of the CB[6]-ADA-HACD complex added as a nanocarrier. Moreover, no detectable fluorescence was observed in these two cell lines after mixing with the ADA-HACD complex (Fig. 6b,e). In the presence of $\mathrm{CB}[6]$, only faint fluorescence was detected in NIH3T3 cells; bright green fluorescence was observed in PC-3 cells under the same experimental conditions (Fig. 6c,f). These results clearly reveal that FAM-siRNA is delivered into cancer cells by receptor-mediated internalization. More importantly, CB[6] plays a primary role in promoting the RNA-binding process in the $\mathrm{CB}[6]-\mathrm{ADA}-\mathrm{HACD}$ system.

Evaluation of EGFP gene silencing effect. As discussed above, the supramolecular CB[6]-ADA-HACD assembly can tightly bind to siRNA to form compact nanoparticles. Having confirmed that these nanoparticles are non-cytotoxic and can be internalized specifically into cancer cells, we then performed exogenetic EGFP (enhanced green fluorescent protein) gene silencing experiments to evaluate the siRNA transfection efficiency of the nanoparticles in vitro (see Supplementary Fig. S37). PC-3 cells were first treated with Lipofectamine 2000 and EGFP-pDNA complex as a negative control. Such treatment would efficiently introduce the EGFP gene into cells, resulting in cells expressing green fluorescent protein. Then, the EGFP-siRNA bound by some conventional transfection reagents, ADA-containing binary complexes, and $\mathrm{CB}[6]-\mathrm{ADA}-\mathrm{HACD}$ assembly was added to PC-3 cells, respectively. As shown in Fig. 7a-f, PC-3 cells emitted bright green fluorescence due to transfection with EGFP-pDNA by Lipofectamine 2000. Treatment with free EGFP-siRNA alone did not result in EGFP-silencing in PC-3 cells; free siRNA cannot be internalized into cells and is easily degraded by ribonuclease (RNase) enzymes ${ }^{52}$. However, EGFP-siRNA complexed with Lipofectamine 2000 conferred moderate EGFP-gene silencing effects; the number of cells emitting green fluorescence and the fluorescence intensity of each cell was simultaneously reduced. In contrast, the $\mathrm{CB}[6]-\mathrm{ADA}-\mathrm{HACD}$ assembly with EGFP-siRNA conferred a greater EGFP-gene silencing effect in PC-3 cells with enhanced global quenching than that observed in the control groups (Fig. 7g-1).

The gene knockdown level was also determined quantitatively by flow cytometry (FCM). As shown in Fig. $7 \mathrm{~m}$, $\mathrm{n}$, although the number of fluorescent cells was comparable to that of the negative control, the fluorescence intensity sharply decreased after treatment with Lipofectamine $2000+$ EGFP-siRNA. These results are indicative of the moderate gene delivery efficiency of Lipofectamine 2000. Moreover, the ADA-HACD complex could not exhibit obvious gene transfection efficiency under the same experimental conditions. In particular, when an excess amount of HA polymer was used to block the receptors on the PC-3 cancer cell surface or the targeting unit HACD was removed in the ADA-CB[6] complex, it is found that the nanocarrier lost its original cell recognition ability, thus resulting in a relatively lower gene transfection efficiency. These results further verify the HA receptor-targeted internalization process in cancer cells. Therefore, benefiting from both CB[6] enhanced siRNA binding capability and targeted internalization in cancer cells, our supramolecular nanoparticle composed of CB[6]-ADA-HACD and EGFP-siRNA exhibited a greater gene knockdown efficiency and a reduced fluorescence intensity in PC-3 cells, which resulted in a gene delivery capacity comparable to the commercial transfection reagent Lipofectamine RNAiMAX, but much greater than Lipofectamine 2000 and X-tremeGENE. Taken together, these results suggest that the $\mathrm{CB}[6]-\mathrm{ADA}-\mathrm{HACD}$ ternary assembly possesses relatively high gene transfection efficacy and can maintain high cell viability simultaneously. 

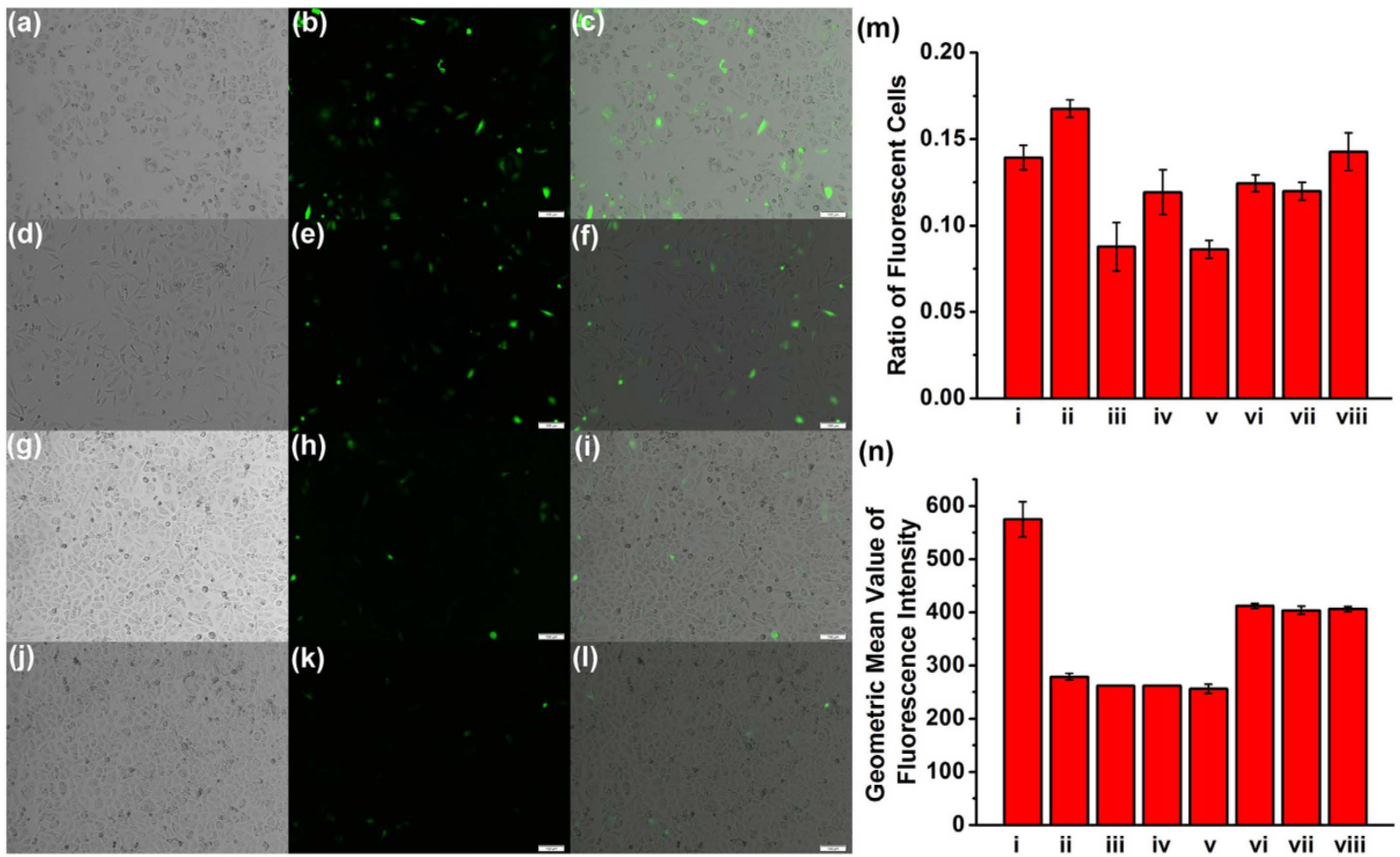

Figure 7. Exogenous EGFP gene silencing effect. Bright-field, fluorescence, and merged images of PC-3 cells after treatment with (a-c) Lipofectamine 2000 + EGFP-pDNA (negative control); and Lipofectamine $2000+$ EGFP-pDNA followed by (d-f) EGFP-siRNA, (g-i) Lipofectamine 2000 + EGFP-siRNA, (j-l) CB[6]ADA-HACD + EGFP-siRNA (experimental group), respectively. (m) Ratios and (n) geometric mean values of fluorescence intensity of fluorescent PC-3 cells according to the results of the FCM experiments: (i) negative control; and Lipofectamine 2000 + EGFP-pDNA followed by (ii) Lipofectamine 2000 + EGFP-siRNA, (iii) Lipofectamine RNAiMAX + EGFP-siRNA, (iv) X-tremeGENE + EGFP-siRNA, (v) experimental group, (vi) CB[6]-ADA-HACD + HA + EGFP-siRNA, (vii) CB[6]-ADA + EGFP-siRNA, and (viii) HACD-ADA + EGFPsiRNA, respectively.

\section{Conclusions}

In conclusion, for the first time, by implementing the supramolecular $\mathrm{p} K_{\mathrm{a}}$ shift concept, we successfully constructed a controlled, targeted and biocompatible nucleic acid binding system, which was achieved by a combined strategy using a supramolecular $\mathrm{p} K_{\mathrm{a}}$ shift and selective self-assembly to realize an efficient nanoparticulate formation using a triad guest ADA with one adamantyl head group and two diamine tails. The adamantyl head group was intended to be selectively bound to $\beta$ - $\mathrm{CD}$, while the diamine tails were to be bound to $\mathrm{CB}[6] .{ }^{1} \mathrm{H}$ NMR spectral examinations of a solution containing ADA, $\beta$-CD, and $\mathrm{CB}[6]$ revealed the exclusive formation of a $\beta$-CDADA-CB [6] ternary complex. Further assembly with $\beta$-CD-modified HA endowed the ability to target cancer cells to this macrocycle-based nanoarchitecture. The noncovalent entrapment of the diamine moiety of ADA with $\mathrm{CB}[6]$ enhanced the binding affinity to siRNA by a macrocycle-induced $\mathrm{p} K_{\mathrm{a}}$ shift, which eventually resulted in siRNA condensation into nanospheres through electrostatic attraction. In cellular experiments, the resulting assembly functioned as a supramolecular non-viral vector in targeted siRNA binding and interference. We also envision that in addition to the enhancement of drug bioavailability, the concept of complexation-induced $\mathrm{p} K_{\mathrm{a}}$ shifts can be applied not only to small drug and dye molecules but also to biofunctional polyamines. This straightforward method provides an attractive and unique tool for controlling the capture and release of other pharmaceutical nucleic acids. Further comparative studies of complexation with various amines are currently in progress.

\section{Methods}

Reagents. All chemical reagents were commercially available unless noted otherwise. The $\beta$-CDappended HA was synthesized according to the reported procedures ${ }^{32}$. NMR data were recorded on 300 and $400 \mathrm{MHz}$ spectrometers. TEM images were acquired using a transmission electron microscope operating at an accelerating voltage of $200 \mathrm{kV}$. The sample for TEM measurements was prepared by dropping a sample solution onto a copper grid. The grid was then air-dried. AFM experiments were performed in tapping mode in air at room temperature. All ${ }^{1} \mathrm{H}$ NMR chemical shifts were referenced to the internal signal of acetone at $2.22 \mathrm{ppm}$ or acetonitrile at $2.06 \mathrm{ppm}^{53}$. For cellular experiments, the conventional transfection reagents (i.e., Lipofectamine 2000, Lipofectamine RNAiMAX, and X-tremeGENE) were purchased from commercial resources. Negative control siRNA (NC-siRNA) and fluorescence labeled FAM-siRNA of the antisense strand 5'-ACGUGACACGUUCGGAGAATT-3' were purchased from GenePharma Co. Ltd. (Shanghai, China), 
EGFP-siRNA of the target sequence 5'-GCAAGCTGACCCTGAAGTTC-3' from Dharmacon, and Hs_FKBP5_5 siRNA of the antisense strand 5'-AUGCUCAAUCUGUUUACCCGT-3' from QIAGEN. The statistical analysis of the data was carried out using the Student's $t$ test. Differences were considered statistically significant if the $p$ value was $<0.05$.

$\mathrm{p} K_{\mathrm{a}}$ measurement by potentiometric titration. The $\mathrm{p} K_{\mathrm{a}}$ values were determined by using the following equation (1):

$$
\frac{\bar{n}_{\mathrm{H}}}{\left(1-\bar{n}_{\mathrm{H}}\right) \times[\mathrm{H}]}=\frac{1}{K_{\mathrm{a}, 1} \times K_{\mathrm{a}, 2}} \times \frac{\left(2-\bar{n}_{\mathrm{H}}\right) \times[\mathrm{H}]}{\left(1-\bar{n}_{\mathrm{H}}\right)}+\frac{1}{K_{\mathrm{a}, 2}}
$$

where $K_{\mathrm{a}, 1}$ and $K_{\mathrm{a}, 2}$ are the acidity constants for dissociation of the first and second protons, respectively, and while $\bar{n}_{\mathrm{H}}$ is defined as the mean number of bounded protons and calculated by using the following equation (2):

$$
\bar{n}_{\mathrm{H}}=\frac{\left[\mathrm{Br}^{-}\right]+\left[\mathrm{OH}^{-}\right]-\left[\mathrm{H}^{+}\right]-\left[\mathrm{K}^{+}\right]}{c_{\mathrm{DAB}}}
$$

where $c_{\mathrm{DAB}}$ is the total concentration of investigated $\mathrm{DAB} ;\left[\mathrm{Br}^{-}\right]$is the concentrations of bromide ion in $\mathrm{DAB}$, $\left[\mathrm{OH}^{-}\right]$is the concentration of hydroxyl ions in aqueous solution, $\left[\mathrm{H}^{+}\right]$is the concentration of the free hydronium ions determined by $\mathrm{pH}$ measurement, and $\left[\mathrm{K}^{+}\right]$is the concentration of added $\mathrm{KOH}$, respectively. Accordingly, the species distribution of doubly protonated $\mathrm{DAB}\left(\mathrm{H}_{2} \mathrm{DAB}\right)$ at the physiological $\mathrm{pH}(7.20)$ could be calculated by the following equation $(3)^{54}$ :

$$
\left[\mathrm{H}_{2} \mathrm{DAB}\right] \%=\frac{1}{1+10^{\mathrm{pH}-\mathrm{p} K_{\mathrm{a}, 1}}+10^{2 \mathrm{pH}-\mathrm{p} K_{\mathrm{a}, 1}-\mathrm{p} K_{\mathrm{a}, 2}}}
$$

Association constant $\left(K_{\mathrm{a}}\right)$ determination. The association constant $\left(K_{\mathrm{a}}\right)$ for a stoichiometric $1: 1$ complex of ADA with native $\beta$-CD was calculated by using the non-linear least-squares fit of the titration data to the following equation $(4)^{55}$ :

$$
\Delta \Delta \delta=\frac{1}{2}\left\{\varepsilon\left([\mathrm{H}]_{0}+[\mathrm{G}]_{0}+\frac{1}{K_{\mathrm{a}}}\right) \pm \sqrt{\varepsilon^{2}\left([\mathrm{H}]_{0}+[\mathrm{G}]_{0}+\frac{1}{K_{\mathrm{a}}}\right)^{2}-4 \varepsilon^{2}[\mathrm{H}]_{0}[\mathrm{G}]_{0}}\right\}
$$

where $\Delta \Delta \delta$ is the NMR chemical shift change of ADA upon addition of native $\beta$-CD and defined as $\Delta \Delta \delta=\Delta \delta$ (with $\beta$-CD) $-\Delta \delta$ (without $\beta$-CD), $\varepsilon$ is the sensitivity factor, and $[\mathrm{H}]_{0}$ and $[\mathrm{G}]_{0}$ are the initial concentrations of native $\beta$-CD and $\mathrm{ADA}$, respectively.

Isothermal titration calorimetry (ITC) measurements. The ITC experiments were performed by an isothermal titration microcalorimeter at atmospheric pressure and at $25.00^{\circ} \mathrm{C}$ in aqueous solution, giving the association constants $\left(K_{\mathrm{a}}\right)$ and the thermodynamic parameters of DAB upon complexation with $\mathrm{CB}[6]$. A solution of $\mathrm{CB}[6](1.868 \mathrm{mM})$ in a $0.250 \mathrm{~mL}$ syringe was sequentially injected with stirring at $300 \mathrm{rpm}$ into a solution of DAB $(0.1744 \mathrm{mM})$ in the sample cell $(1.4227 \mathrm{~mL}$ volume). All the thermodynamic parameters reported in this work were obtained by using the 'one set of binding sites' model. Two independent titration experiments were performed to afford self-consistent parameters and to give the averaged values.

Agarose gel electrophoresis assay. Agarose gel electrophoresis experiments were performed in TAE buffer $(0.04 \mathrm{M}$ Tris, $0.02 \mathrm{M}$ acetic acid, and $2.0 \mathrm{mM}$ ethylenediaminetetraacetic acid (EDTA) $)$ at $25^{\circ} \mathrm{C}$. Following electrophoresis, siRNA bands were stained in an ethidium bromide (EB) solution and were visualized under UV light at $302 \mathrm{~nm}$. The condensation ability of the resulting complexes and assemblies to siRNA was measured by analyzing the electrophoretic mobility at different N/P ratios on agarose gel. In the electrophoresis assay, the N/P ratio is defined as the ratio of positively charged ammoniums in ADA to negatively charged phosphates in siRNA; the molar ratio of $\mathrm{CB}[6]$ to $\mathrm{ADA}$ was fixed at 2:1. Gene transfection and cytotoxicity studies were performed at $\mathrm{N} / \mathrm{P}=20$, the optimal condition for siRNA condensation, as determined in Supplementary Fig. S34.

Cytotoxicity experiments. PC-3 human prostatic cancer cells were cultured for $24 \mathrm{~h}$ in RPMI-1640 medium, which was supplemented with $10 \%$ fetal bovine serum (FBS), in 96 -well plates $\left(5 \times 10^{4}\right.$ cells $\mathrm{mL}^{-1}$, $100 \mu \mathrm{L}$ per well). The cells were incubated with ADA, ADA-CB[6], ADA-HACD, and CB[6]-ADA-HACD complexes at different concentrations; $[\mathrm{ADA}]=20,40,80$, and $160 \mu \mathrm{M}$ and $[\mathrm{CB}[6]]=2[\mathrm{ADA}]=34[\mathrm{HACD}]$. After incubation for 24 and $48 \mathrm{~h}$, the relative cellular viability was determined by the MTT (3-(4,5-dimet hylthiazol-2-yl)-2,5-diphenyltetrazolium bromide) assay. All data are presented as the mean \pm standard deviation.

In the comparative study, the PC-3 human prostatic cancer cells were incubated with 1 equiv ternary assembly $([\mathrm{CB}[6]]=2[\mathrm{ADA}]=34[\mathrm{HACD}]=34 \mu \mathrm{M}), 10$ equiv ternary assembly $([\mathrm{CB}[6]]=2[\mathrm{ADA}]=34[\mathrm{HACD}]=$ $340 \mu \mathrm{M}), 1$ equiv Lipofectamine $2000(1.5 \mu \mathrm{L}$ in $1 \mathrm{~mL} 1640$ medium), and 10 equiv Lipofectamine $2000(15 \mu \mathrm{L}$ in $1 \mathrm{~mL} 1640$ medium), respectively. After incubation for $24 \mathrm{~h}$, the relative cellular viability was measured with MTT assay. All the loading concentrations of the commercial transfection reagents were used according to the manufacturer's instruction. All data are presented as the mean \pm standard deviation (see Supplementary Fig. S35). 
Fluorescence imaging experiments. PC-3 cells were cultured in RPMI-1640 medium, and NIH3T3 mouse embryonic fibroblasts were cultured for $24 \mathrm{~h}$ in Dulbecco's modified Eagle's medium (DMEM), which were supplemented with $10 \% \mathrm{FBS}$, in 6 -well plates $\left(1 \times 10^{5}\right.$ cells $\mathrm{mL}^{-1}, 2 \mathrm{~mL}$ per well $)$. Then, $\mathrm{CB}[6]-\mathrm{ADA}-\mathrm{HACD}$ assembly $([\mathrm{CB}[6]]=2[\mathrm{ADA}]=34[\mathrm{HACD}]=34 \mu \mathrm{M})$ with FAM-labeled NC-siRNA $(80 \mathrm{nM}, \mathrm{N} / \mathrm{P}=20)$ was added to the culture medium. After incubation for $5 \mathrm{~h}$, the medium was discarded, the cells were washed by fresh cold PBS, and then the fresh medium was added. The cells were examined by fluorescence microscopy.

EGFP gene silencing experiments. PC-3 cells were cultured for $24 \mathrm{~h}$ in RPMI-1640 medium, which was supplemented with $10 \% \mathrm{FBS}$, in 6 -well plates $\left(2 \times 10^{5}\right.$ cells $\mathrm{mL}^{-1}, 2 \mathrm{~mL}$ per well). Then, the culture medium was removed and the FBS-free 1640 medium containing Lipofectamine 2000 ( $2 \mu \mathrm{L}$ per $1 \mathrm{~mL} 1640$ medium) and EGFP-pDNA ( $1.9 \mu \mathrm{g}$ per $1 \mathrm{~mL} 1640$ medium) was added to the culture plates. After incubation for $3 \mathrm{~h}$, the medium was discarded and full component 1640 medium (containing FBS), full component 1640 medium containing EGFP-siRNA $(80 \mathrm{nM})$, FBS-free 1640 medium containing Lipofectamine $2000(1.5 \mu \mathrm{L}$ per $1 \mathrm{~mL} 1640$ medium) and EGFP-siRNA $(80 \mathrm{nM})$ which was replaced by fresh full component 1640 medium after another $4 \mathrm{~h}$, and full component 1640 medium containing $\mathrm{CB}[6]-\mathrm{ADA}-\mathrm{HACD}([\mathrm{CB}[6]]=2[\mathrm{ADA}]=34[\mathrm{HACD}]=34 \mu \mathrm{M})$ and EGFP-siRNA $(80 \mathrm{nM}, \mathrm{N} / \mathrm{P}=20)$ were added to the culture plates. After incubation for another $24 \mathrm{~h}$, the cells were examined by fluorescence microscope and then dissociated by trypsin for FCM measurements.

\section{References}

1. Hanoian, P., Liu, C. T., Hammes-Schiffer, S. \& Benkovic, S. Perspective on electrostatic and conformational motions in enzyme catalysis. Acc. Chem. Res. 48. 482-489 (2015).

2. Lippert, B. Ligand- $\mathrm{p} K_{\mathrm{a}}$ shifts through metals: potential relevance to ribozyme chemistry. Chem. Biodiversity 5, 1455-1474 (2008).

3. Forsyth, W. R., Antosiewicz, J. M. \& Robertson, A. D. Empirical relationships between protein structure and carboxyl $\mathrm{p} K_{\mathrm{a}}$ values in proteins. Proteins: Struct., Funct., Bioinf. 48, 388-403 (2002).

4. Harris, T. K. \& Turner, G. J. Structure basis of perturbed $\mathrm{p} K_{\mathrm{a}}$ values of catalytic groups in enzyme active sites. IUBMB Life $53,85-98$ (2002).

5. Takemoto, H. et al. Acidic pH-responsive siRNA conjugate for reversible carrier stability and accelerated endosomal escape with reduced IFNa-associated immune response. Angew. Chem. Int. Ed. 52, 6218-6221 (2013).

6. Zhang, L. et al. Hydrolytic cationic ester microparticles for highly efficient DNA vaccine delivery. Small 9, 3439-3444 (2013).

7. Liu, X., Yang, J. W. \& Lynn, D. M. Addition of "charge-shifting" side chains to liner poly(ethyleneimine) enhances cell transfection efficiency. Biomacromolecules 9, 2063-2071 (2008).

8. Shao, Q. \& Jiang, S. Molecular understanding and design of zwitterionic materials. Adv. Mater. 27, 15-26 (2015).

9. Xie, J. \& Bogliotti, N. Synthesis and applications of carbohydrate-derived macrocyclic compounds. Chem. Rev. 114, 7678-7739 (2014).

10. Strutt, N. L., Zhang, H., Schneebeli, S. T. \& Stoddart, J. F. Functionalizing pillar[n]arenes. Acc. Chem. Res. 47, 2631-2642 (2014).

11. Kaifer, A. E. Toward reversible control of cucurbit $[n]$ uril complexes. Acc. Chem. Res. 47, 2160-2167 (2014).

12. Ma, X. \& Tian, H. Bright functional rotaxanes. Chem. Soc. Rev. 39, 70-80 (2010).

13. Simões, S. M. N., Rey-Rico, A., Concheiro, A. \& Alvarez-Lorenzo, C. Supramolecular cyclodextrin-based drug nanocarriers. Chem. Commun. 51, 6275-6289 (2015).

14. Sansone, F. \& Casnati, A. Multivalent glycocalixarenes for recognition of biological macromolecules: glycocalyx mimics capable of multitasking. Chem. Soc. Rev. 42, 4623-4639 (2013).

15. Tong, R. \& Kohane, D. S. Shedding light on nanomedicine. WIREs Nanomed. Nanobiotechnol. 4, 638-662 (2012).

16. Walker, S., Oun, R., McInnes, F. J. \& Wheate, N. J. The potential of cucurbit $n$ ] urils in drug delivery. Isr. J. Chem. 51, 616-624 (2011).

17. Trinh, T. B., Upadhyaya, P., Qian, Z. \& Pei, D. Discovery of a direct ras inhibitor by screening a combinatorial library of cellpermeable bicyclic peptides, ACS Comb. Sci. 18, 75-85 (2016).

18. Ma, X. \& Zhao, Y. Biomedical applications of supramolecular systems based on host-guest interactions. Chem. Rev. 115, 7794-7839 (2015).

19. Andrade, B. et al. New frontiers for encapsulation in the chemical industry. ACS Appl. Mater. Interfaces 7, 6359-6368 (2015).

20. Gürbüz, S., Idris, M. \& Tuncel, D. Cucurbituril-based supramolecular engineering nanostructure materials. Org. Biomol. Chem. 13, 330-347 (2015).

21. Giordanetto, F. \& Kihlberg, J. Macrocyclic Drugs and clinical candidates: what can medicinal chemists learn from their properties? J. Med. Chem. 57, 278-295(2014).

22. Wang, L., Li, L.-L., Fan, Y.-S. \& Wang, H. Host-guest supramolecular nanosystems for cancer diagnostics and therapeutics, Adv. Mater. 25, 3888-3898 (2013).

23. Barooah, N., Mohanty, J., Pal, H. \& Bhasikuttan, A. C. Cucurbituril-induced supramolecular $\mathrm{p} K_{\mathrm{a}}$ shift in fluorescent dyes and its prospective applications. Proc. Natl. Acad. Sci., India, Sect. A Phys. Sci. 84, 1-17 (2014).

24. Ghosh, I. \& Nau, W. M. The strategic use of supramolecular $\mathrm{p} K_{\mathrm{a}}$ shifts to enhance the bioavailability of drug. Adv. Drug. Delivery Rev. 64, 764-783 (2012)

25. Berezhnoy, N. V., Korolev, N. \& Nordenskiöld, L. Principles of electrostatic interactions and self-assembly in lipid/peptide/DNA systems: applications to gene delivery. Adv. Colloid Interf. Sci. 205, 221-229 (2014).

26. Schroeder, A., Levins, C. G., Cortez, C., Langer, R. \& Anderson, D. G. Lipid-based nanotherapeutics for siRNA delivery. J. Int. Med. 267, 9-21 (2010).

27. Zhang, Y.-M., Cao, Y., Yang, Y., Chen, J.-T. \& Liu, Y. A small-sized graphene oxide supramolecular assembly for targeted delivery of camptothecin. Chem. Commun. 50, 13066-13069 (2014).

28. Liu, G. et al. Sticky nanoparticles: a platform for siRNA delivery by a bis(zinc(II) dipicolylamine)-functionalized, self-assembled nanoconjugate. Angew. Chem. Int. Ed. 51, 445-449 (2012).

29. Choi, K.-m., Jang, M., Kim, J. H. \& Ahn, H. J. Tumor-specific delivery of siRNA using supramolecular assembly of hyaluronic acid nanoparticles and 2b RNA-binding protein/siRNA complexes. Biomaterials 35, 7121-7132 (2014).

30. Kulkarni, A., DeFrees, K., Hyun, S.-H. \& Thompson, D. H. Pendant polymer:amino-beta-cyclodextrin:siRNA guest:host nanoparticles as efficient vectors for gene silencing. J. Am. Chem. Soc. 134, 7596-7599 (2012).

31. Itaka, K. et al. Supramolecular nanocarrier of siRNA from PEG-based block catiomer carrying diamine side chain with distinctive $\mathrm{p} K_{\mathrm{a}}$ directed to enhance intracellular gene silencing. J. Am. Chem. Soc. 126, 13612-13613 (2004).

32. Yang, Y., Zhang, Y.-M., Chen, Y., Chen, J.-T. \& Liu, Y. Targeted polysaccharide nanoparticle for adamplatin prodrug delivery. J. Med. Chem. 56, 9725-9736 (2013).

33. Kwon, Y. J. Before and after endosomal escape: roles of stimuli-converting siRNA/polumer interactions in determining gene silencing efficiency. Acc. Chem. Res. 45, 1077-1088 (2012).

34. Bruno, K. Using drug-excipient interactions for siRNA delivery. Adv. Drug. Delivery Rev. 63, 1210-1226 (2011). 
35. Reischl, D. \& Zimmer, A. Drug delivery of siRNA therapeutics: potentials and limits of nanosystems. Nanomed: Nanotechnol. Biol. Med. 5, 8-20 (2009).

36. Liu, Y., You, C.-C., Wada, T. \& Inoue, Y. Molecular recognition studies on supramolecular systems. 22. Size, shape, and chiral recognition of aliphatic alcohols by organoselenium-modified cyclodextrins. J. Org. Chem. 64, 3630-3634 (1999).

37. Zhang, Y.-M., Chen, Y., Li, Z.-Q., Li, N. \& Liu, Y. Quinolinotriazole- $\beta$-cyclodextrin and its adamantanecarboxylic acid complex as efficient water-soluble fluorescent $\mathrm{Cd}^{2+}$ sensors. Bioorg. Med. Chem. 18, 1415-1420 (2010).

38. Lagona, J., Mukhopadhyay, P., Chakrabarti, S. \& Isaacs, L. The cucurbit[n] uril family. Angew. Chem. Int. Ed. 44, 4844-4870 (2005).

39. Such, G. K., Yan, Y., Johnston, A. P. R., Gunawan, S. T. \& Caruso, F. Interfacing materials science and biology for drug carrier design. Adv. Mater. 27, 2278-2297 (2015).

40. Shen, Y., Hu, G., Zhang, H., Qi, L. \& Luo, C. Recent progress in pH-sensitive gene carriers. Acta Chim. Sinica 71, 323-333 (2013).

41. Park, I.-K. et al. pH-responsive polymers as gene carriers. Macromol. Rapid Commun. 311, 122-1133 (2010).

42. Gao, W., Chan, J. M. \& Farokhzad, O. C. pH-responsive nanoparticles for drug delivery. Mol. Pharm. 7, 1913-1920 (2010).

43. Bakirci, H., Koner, A. L., Schwarzlose, T. \& Nau, W. M. Analysis of host-assisted guest protonation exemplified for $p$-sulfonatocalix[4] arene-towards enzyme-mimetric $\mathrm{p} K_{\mathrm{a}}$ shifts. Chem. Eur. J. 12, 4799-4807 (2006).

44. Zhang, Q.-F. et al. Liner polycations by ring-opening polymerization as non-viral gene delivery vectors. Biomaterials 34, 5391-5401 (2013).

45. Liu, H., Wang, H., Yang, W. \& Cheng, Y. Disulfide cross-linked low generation dendrimers with high gene transfection efficiency, low cytotoxicity, and low cost. J. Am. Chem. Soc. 134, 17680-17687 (2012).

46. Zintchenko, A., Philipp, A., Dehshahri, A. \& Wagner, E. Simple modification of branched PEI lead to highly efficient siRNA carriers with low toxicity. Bioconjugate Chem. 19, 1448-1455 (2008).

47. Jeong, J. H. et al. Reducible poly(amido ethylenimine) directed to enhance RNA interference. Biomaterials 28, 1912-1917 (2007).

48. Scholz C. et al. Correlation of length of liner oligo(ethanamino) amides with gene transfer and cytotoxicity. ChemMedChem 9, 2104-2110 (2014).

49. Tsutsumi, T., Hirayama, F., Uekama, K. \& Arima, H. Evaluation of polyamidoamine dendrimer/ $\alpha$-cyclodextrin conjugate (generation 3, G3) as a novel carrier for small interfering RNA (siRNA). J. Control. Release 119, 349-359 (2007).

50. Mansouri. S. et al. Characterization of folate-chitosan-DNA nanoparticles for gene therapy. Biomaterials 27, 2060-2065 (2006).

51. Ni, X.-L. et al. Self-assemblies based on the "outer-surface interactions" of cucurbit $[n]$ urils: new opportunities for supramolecular architectures and materials. Acc. Chem. Res. 47, 1386-1395 (2014).

52. Pérez-Martínez, F. C. et al. Enhanced docetaxel-mediated cytotoxicity in human prostate cancer cells through knockdown of cofilin-1 by carbon nanohorn delivered siRNA. Biomaterials 33, 8152-8159 (2012).

53. Gottlieb, H. E., Kotlyar, V. \& Nudelman, A. NMR chemical shifts of common laboratory solvents as trace impurities. J. Org. Chem. 62, 7512-7515 (1997).

54. Wenz, G. et al. Recognition of ionic guests by ionic $\beta$-cyclodextrin derivatives. Chem. Eur. J. 14, 7202-7211 (2008).

55. Inoue, Y. et al. Inclusion complexation of (cyclo)alkanes and (cyclo)alkanols with 6-O-modified cyclodextrins. J. Chem. Soc., Perkin Trans. 2, 1807-1816 (1998).

\section{Acknowledgements}

We thank the National Natural Science Foundation of China (Nos 21432004, 21472100, and 91527301) for financial support.

\section{Author Contributions}

Y.-M.Z. synthesized and characterized the functionalized ternary assembly. Y.Y. and Y.-H.Z. conducted the siRNA-binding and cellular experiments. All authors analyzed and discussed the results. Y.-M.Z. and Y.Y. wrote the main manuscript and prepared figures. Y.L. supervised the work and edited the manuscript. All authors reviewed the manuscript.

\section{Additional Information}

Supplementary information accompanies this paper at http://www.nature.com/srep

Competing financial interests: The authors declare no competing financial interests.

How to cite this article: Zhang, Y.-M. et al. Polysaccharide Nanoparticles for Efficient siRNA Targeting in Cancer Cells by Supramolecular $\mathrm{p} K_{\mathrm{a}}$ Shift. Sci. Rep. 6, 28848; doi: 10.1038/srep28848 (2016). unless indicated otherwise in the credit line; if the material is not included under the Creative Commons license, users will need to obtain permission from the license holder to reproduce the material. To view a copy of this license, visit http://creativecommons.org/licenses/by/4.0/ 